\title{
SOCIAL DETERMINANTS OF INFECTIOUS DISEASES IN DIVERSE AGE GROUPS IN VARNA REGION, BULGARIA
}

\author{
Gospodinova M., K. Stoyanova, M. Nenova \\ Department of Infectious Diseases, Epidemiology and Tropical Medicine, \\ Faculty of Public Health, Medical University of Varna, Bulgaria
}

Reviewed by: assoc. prof. St. Popova

\begin{abstract}
During the first years as a member to the European Union the healthcare system of Republic of Bulgaria faced many challenges: declining demographic tendencies, poverty with noticeably expressed age dimensions and limited resources for health care. The aim of this study is to reveal some social determinants and risk factors in the vulnerable groups of elderly people and breast-fed infants with communicable diseases. Specially designed questionnaires were used to study the socioeconomic and other risk factors in patients over 60 years and mothers accompanying their infants with infectious diseases. Analyses of the demographic indicators of Varna region and disease incidence correspond to the trends of the national level. Infectious diseases most commonly observed among the aged population are shigelloses, salmonelloses and other gastroenterites, Mediterranean spotted fever, lymeborreliosis, acute viral hepatitis and neuroinfections. Gastroenterites in breast-fed infants are the most common cause for hospitalization. The risk factors influencing patients of $60+$ suffering from infectious diseases are poverty, unhealthy and inadequate nutrition, smoking, alcohol consumption, insufficient physical activity and high levels of stress. Socially significant incommunicable diseases are the common terrain on which the infectious process takes place. Risk factors influencing infants with infectious diseases are similar and sometimes derived from the factors influencing the adult population. More detailed and wider span studies of the social determinants of comunicable diseases in Bulgaria are needed to estimate the situation in other risk groups.
\end{abstract}

Key words: vulnerable groups, elderly people, breast-fed infants, infectious disease, social risk factors

\section{INTRODUCTION}

\section{Social situation and demographic development of Bulgaria}

In the period when Republic of Bulgaria prepared for the accession to the European Union (EU) and during its first years as a full member, the health services faced many challenges:

- Orientation to the patient

- Improving the quality of medical care

- Implementation of these tasks in a situation of chronic financial deficit

Despite some tendencies for a stable economic growth and (1) "improvement of employment and consolidating the processes of territorial and social cohesion", the demographic development and provision of equal access of various risk groups to main services, mainly in the fields of ed-

Address for correspondence:

M.Gospodinova, Dept. of Infectious diseases, Medical University of

Varna, 55 Marin Drinov str, Varna 9000

e-mail:dr_m_gospodinova@abv.bg ucation and medical care in Bulgaria, remained quite unfavourable. There exists a lasting tendency for decline in the population number and negative growth. In 2007 the population was 7640000 people. For the last 16 years it has decreased with about 1 million. In 2020 it will drop with another 450000 people. The natural growth is negative and varies about minus 5 per one thousand. In 2007 the birth rate reached $9.8 \%$. The death rate was $14.6-14.8 \%$.

The average life expectancy in Bulgaria is 68.9 years for men and 76.0 for women (with about 6.5 years less than for the rest EU) $(2,3)$. Prognoses show that, the ratio between people over 65 years of age and the active population (1564 years of age) will increase from $25 \%$ to $30 \%$. According to data from the United Nations our country holds the ninth place in the world in percentage of people of advanced and old age. The Bulgarian population ages with "a model of pathologic old age" (4). The ageing process has its consequences in all spheres of life: health care, employment, social security, etc. $(2,3,5,6)$. In countries which pass through a period of economic and social transformation this process is combined with decrease of the financial resources and impoverishment of the population. 


\section{Standard of life and levels of poverty}

In 2007 the gross national product (GNP) per head of the population was $3800 €$, which is $38 \%$ of that of the EU. The risk of poverty reaches $14.1 \%$ and shows markedly expressed age dimensions. In 2003 a line of poverty of 102 levs was defined $(1 €=1.95$ levs). Every seventh Bulgarian had a threshold level beneath that of 102 levs. The share of the extremely poor households ranges between $2.3 \% \mathrm{Na}-$ tional Statistical Institute (NSI) and 7.9\% (World Bank) (7). Below the relative threshold level of poverty (defined as $60 \%$ of the median equivalent income and adopted by EUROSTAT and the NSI) there live $13.43 \%$ of Bulgarian households. In 2007 the line of poverty was determined as 152 levs, and since 1 January 2008 it is 166 levs. In 2007 $18.8 \%$ of the children up to the age of 15 and $17.7 \%$ of people over 65 have lived in poverty. The percentage of senior citizens that live on a pension in Bulgaria is $20.6 \%$.

The negative demographic development and the existing unfavourable social tendencies face the limited resources for health care. For 2007 the resources for health care are $4.2 \%$ of the GNP, i.e. $132 €$ per person ( $1710 €$ in the EU). The financing is provided by the Ministry of Health and $66 \%$ of them by the National Health Insurance Fund (1).

The National Report on Strategies for Social Protection and Social Inclusion (2008-2010) (1) points out following most vulnerable groups:

- Unemployable people: children, old people

- Families with children: single parents, families with many children

- People with disabilities

- Gypsies

The observed socio-economic tendencies have affected all sections of the health care system, including the dissemination of contagious diseases and their control. The changes in the traditional system of epidemiological control and the withdrawal of a number of state institutions from the financing of the diagnostics and treatment of infectious diseases (ID) have had a negative effect on the morbidity and mortality related to them. The structure of infectious morbidity has changed significantly, some diseases have been eradicated or reduced to a minimum while others take up their place: new and re-emerging infections, HIV/AIDS ( 878 cases by the end of 2007), active tuberculosis (40 cases per 100,000) etc. (8).

The control over infectious diseases in Bulgaria is performed by various institutions with about 180 epidemiologists, all under the management of the Ministry of Health. The treatment of infectious diseases is carried out at home, or in specialized clinics where the beds continually decrease (7). The number of specialists in infectious diseases is also reduced significantly, being approximately 160 people.

\section{THE AIM}

The aim of this study is to reveal some social determinants and risk factors for infectious diseases in the vulnerable groups of adults over 60 years of age and breast-fed infants up to 1 year of age.

\section{OBJECTIVES}

1. Studying the demographic tendencies and the morbidity of infectious diseases among the population of Varna region of advanced and old age.

2. Revising some social risk factors in hospitalized patients of $60+$ years with infectious diseases.

3. Studying some social risk factors among breast-fed children with gastroenteritis, that being the most common cause for admission in infectious disease departments at that age.

\section{MATERIALS AND METHODS}

1. Analyses of the demographic indicators of Varna region (data from the National Statistic Institute) and infectious disease incidence for the period of 1997 2007 (data from the Regional Inspectorate for Protection and Control of Public Health) were performed.

2. All 54 patients with tick-borne infections and gastroenteritis between 64 and $85(73.87 \pm 1.83)$ years of age, hospitalized in 2007, in the Department of Infectious Diseases of "St. Marina" University Hospital, Varna were interviewed using a standardized individual questionnaire specially designed for the task to study the socioeconomic and other risk factors. Almost all questions are of the closed type, most of them requiring just one answer. The content of the questions conforms to the recommended by CINDI (Country International Non-communicable Disease Intervention Program) sample questionnaires.

3. 53 mothers with infants treated for gastroenteritis in the same hospital were interviewed using similar questionnaires.

4. Iinquiry, variational and graphic analyzes were used to analyse the data.

\section{RESULTS AND DISCUSSION}

\section{Analysis of the demographic tendencies and morbidity of infectious diseases in Varna region.}

Varna region has a territory of $3,820 \mathrm{~km}^{2}$ and population of 457,922 in $2006.79 .43 \%$ of them live in towns and $20.57 \%$ in villages. About $80 \%$ of the population is in the group of over 18 years of age, including $20.44 \%$ of the people over 60 years of age (8). The health and demographic processes correspond to those on national level: low birth rate of $9.8 \%$; high general mortality of $12.2 \%$; negative growth of minus 2.4. 
The study shows that the infectious diseases most commonly observed among the aged population in Varna region are shigelloses, salmonelloses and other infectious gastroenterites, Mediterranean spotted fever (MSF), lymeborreliosis, acute viral hepatitis and neuroinfections. The total infectious morbidity in the last five years, including people of 60+ years of age varies between $1,150.80 \%$ ooo (the lowest in 2005) and 1,463.58\%ooo (the highest in 2000). With elderly the lowest morbidity is in $2006-201.4 \%$ ooo, and the highest is in $2004-309.8 \%$ ooo. The structure of infectious pathology among the old population in the region is reflected in the structure of the hospitalized by number and nosology patients of $60+$ at the Department for Infectious Diseases of St. Marina University Hospital, Varna $(9,10)$. Co-morbidity was established in $86.33 \%$ of these patients $(9,10)$. Communicable diseases in elderly patients take their course against the adverse demography and health conditions and under the collective impact of multitude of social risk factors.

\section{Risk factors influencing patients of 60+ suffering from infectious diseases.}

Poverty, no matter whether it is determined on the basis of income, socioeconomic status, conditions of living or level of education, appears to be one of the most important determinants for poor health $(1,8)$. Poverty leads to increase of the individual factors of risk, threat for malnutrition, poor living standard, and reduced access to information, as well as reduced opportunities to receive the necessary medical care. Creating a vicious circle, poor health on its own leads to poverty at the expense of reduced productivity, income and quality of life. All patients we interviewed are pensioners. Of them $11.11 \%$ have an income below 100 levs, $72.22 \%$ are with an income of up to 200 levs, $16.67 \%$ have an income over 200 levs. Only 5.55\% have an additional income on top of their pensions, and $35.18 \%$ rely on their own produce for food. Results show that $83.33 \%$ of our interviewees are below the line of poverty as defined for 2008 (1).

Nutrition. The socioeconomic changes in the years after 1989 intensified the unhealthy way of eating. This has created opportunities for emergence of food shortage for the elderly, for increase of people with overweight and obesity, for aggravation of the combinations of major risk factors of various diseases. Malnutrition (energy, protein, of microelements) is just as an important factor as the ageing of the immune system. The economic development and urbanization led to rapid changes in the nutritional habits with increased intake of fats, animal products, refined foods, and reduced intake of fresh vegetables and fibres. This "nutritional transition", is the cause for higher stages of obesity and leads to chronic diseases amplifying the risk of infections $(11,12)$. Liberalization of production, the free import of goods, the lack of strict enough norms of control, create risks for the health from biological, chemical and radioactive contaminants of food. The healthy products are not accessible for the larger part of the population and especially for the elderly who have limited income.
Data from the analysis of our questionnaires shows that the bigger fraction of our elderly patients $(77.78 \%)$ has th healthy habit of having breakfast every morning. More than three times eat only $7.40 \%$ of the interviewed patients; $11.12 \%$ eat twice a day, and $3.70 \%$ eat without any definite order. It is $79.62 \%$ of our patients who eat moderately (compared to data from the CINDI programme with $81.3 \%$ ) (13); $5.56 \%$ estimate that they eat plentifully (this percentage is lower than the $7.7 \%$ from the CINDI), and $11.12 \%$ say they eat frugally (against $2.5 \%$ from CINDI) (14). It is significantly and statistically reliable that most of our elderly people eat frugally, as compared to data from CINDI ( $\mathrm{p}<0.001)$.

Our results show a tendency of reducing the consumption of bread, compared to the data from the CINDI questionnaire (an average of 5.1 slices a day), which may be explained with the continuous impoverishment of the pensioners and the significant increase of the price of bread. Three slices of bread a day consume $53.70 \%$ of the interviewed; $25.93 \%$ take four slices; $11.11 \%$ - five slices; $9.26 \%$ - six slices, and men eat more bread than women. The weekly consumption of main types of food by patients of $60+$ with infectious diseases is shown on Fig. 1.

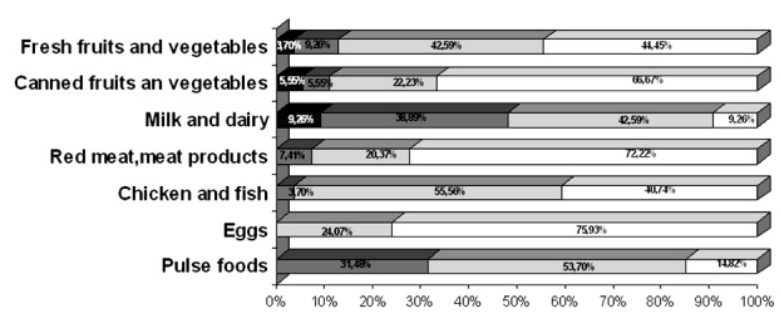

$\square$ every day $\square 3$ times weekly $\square 2$ times we ekly $\square 1$ time weekly

Fig.1. Weekly consumption of main types of food by patients of $60+$ with ID.

As to sweet foods and sugar: $77.78 \%$ of the interviewees consume sweets every day; $68.52 \%$ do it once daily, usually at breakfast; $9.26 \%$ consume them more than once daily; $12.96 \%$ - once a week; and only $9.26 \%$ avoid their consumption. Consumption of sweet foods and sugar has a permanent place on the menu of the elderly interviewees, and it is one of the main reasons for obesity, diabetes, atherosclerosis, etc.

Salt is found in many of the ready and convenience foods so it is difficult to measure its consumption with sufficient precision and to find out exactly how much salt is used at home and during meals. So we asked the interviewees what type of food they use in relation to salt. The salt consumption among them was high. Various questionnaires used over the years in relation to the way of eating of the Bulgarians show that salt for us is a "national disaster". Bulgarians consume 1.5 - 2 times more salt that the Europeans and the Americans $(14,15)$.

Smoking is one of the leading causes for a number of 
chronic diseases and one of the main risk factors for ischemic heart disease and lung cancer.

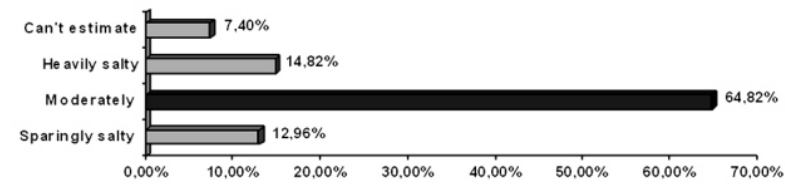

Fig.2. Consumption of salt by patients of $60+$ with ID.

Various questionnaires used in Bulgaria show that about $43.50 \%$ of the population are smokers. The most common reasons for giving up smoking are health reasons. Non-smokers are exposed to the risk influence of passive smoking.

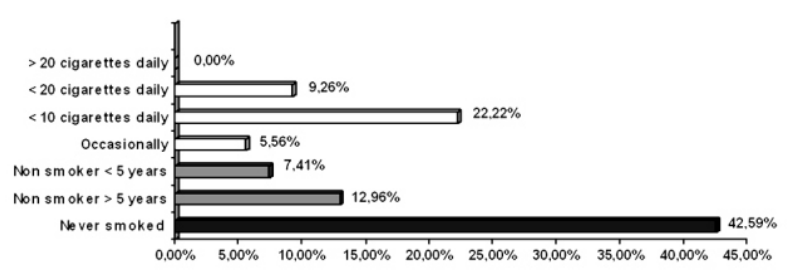

Fig.3. Smoking by elderly patients with ID

Alcohol consumption is a widely spread event among the Bulgarian population (13). Compared with data from the CINDI questionnaire (14), the group of interviewees with high risk alcohol consumption is smaller $(11.11 \%$ against $19.40 \%$ ), $\mathrm{p}<0.001$ (Fig.4).

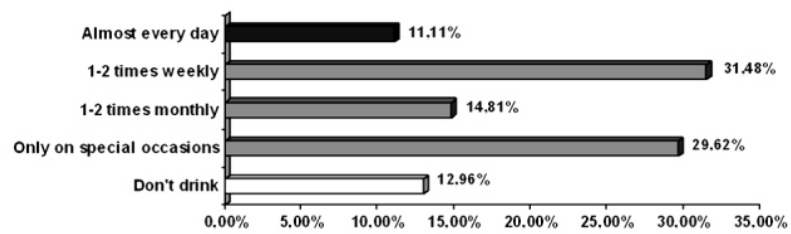

Fig. 4. Alcohol consumption by patients of $60+$ with ID

Physical activity. The physically active way of life is a source of good health and prevents the formation of risk factors. Low physical activity, on the other hand, is associated with a number of diseases: obesity, cardiovascular diseases, cancer, diabetes type -II, etc., and increases expenditure in health care. With a standard for an average physical load of at least 4 hours a week, it is found that the share of persons with high and average physical activity in the country has decreased from $64.4 \%$ to $59.9 \%$ (14). Of those who do any special activities, the share of people living in the villages is higher. The combination of low physical activity with increased blood pressure, increased cholesterol and increased body weight is very common. This accumulation of risk factors increases the risk for the health. Only
$3.70 \%$ of them show the physical activity recommended by the WHO (of at least 1 hour daily).

Stress. The WHO defines health as "a state of complete physical, mental and social welfare and not only absence of disease or physical disability" (2). Nowadays stress has become an unavoidable companion to contemporary life, one of its "symbols". People of $60+$ are subjected to the constant influence of the psychosocial stress. With the advancement of age they feel unwanted, their social contacts decrease, their financial prospects are limited, often because of disease or death of their close ones they remain to live alone, they cannot buy the necessary medicines and healthy foods, have no free access to medical care. The isolation in which the elderly find themselves leads to a decrease of the positive emotional charge, and increase of the frequency of low spirits and depression. In the group of elderly patients who define their self-esteem as very good are those who have additional income, they have not had any serious trouble over the last year and regularly do physical activities and tourism. Those interviewees with permanently low self-esteem have recently lost a close to them person or their way of life has drastically changed due to an illness. Almost half of the interviewed patients (46.29\%) have had serious trouble during the last year. 29.63\% are lonely. Of them $27.78 \%$ judge their self-esteem to be permanently low, $35.19 \%$ as variable, $33.33 \%$ as satisfactory and only $3.70 \%$ as very good.

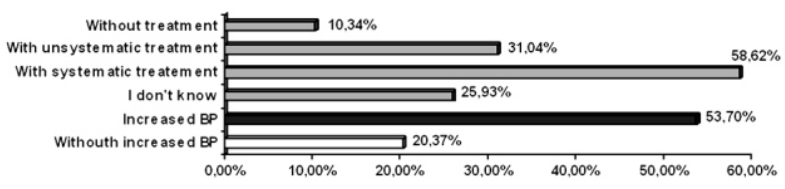

Fig.5. Increased blood pressure (BP) and treatment in patients of $60+$ with ID.

Socially significant diseases. Through the questionnaire we trailed some of the socially significant diseases which define the level of general mortality and cause huge human and material losses thus impeding the development of the country. They are most commonly the pre-morbid terrain on which the infectious process develops.

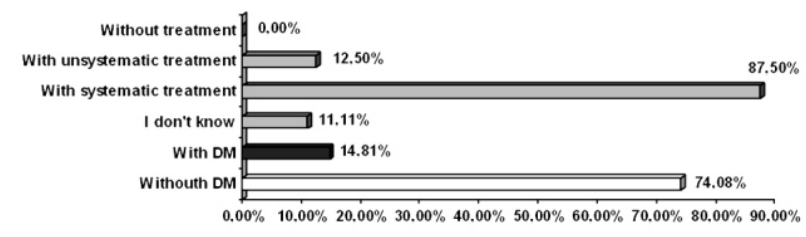

Fig.6. Diabetes mellitus (DM) and treatment in patients of $60+$ with ID 
Half of the investigated persons with hypertension and infectious diseases are current smokers, $2 / 3$ of them give data for reduced movement activities, $27.58 \%$ show consumption of heavily salted food. Presence of concomitant diseases report $72.24 \%$ of the patients of $60+$ : ischemic heart disease, cerebrovascular disease, chronic obstructive pulmonary disease, chronic renal insufficiency, neo-processes, etc.

\section{Conclusions from the questionnaire for the $60+$ patients with infectious diseases:}

- $83.33 \%$ of the patients live below the line of poverty, which decreases their chances for treatment, access to qualified medical care, healthy way of life.

- Nutrition of elderly patients is unhealthy, inadequate as quantity, with wrong ratio of the main constituents. The consumption of fresh fruit and vegetables, of fish, milk and dairy products is insufficient. The consumption of salt is increased.

- The smokers present $37.04 \%$ of the interviewed patients, and the non-smokers are exposed to the risk influence of passive smoking.

- $11.11 \%$ of the patients of $60+$ present with high risk alcohol consumption.

- The elderly patients lead a sedentary life. Only $3.70 \%$ of them show the physical activity over 1 hour recommended by the WHO.

- Patients of $60+$ are subjected to everyday psychosocial stress, and $46.29 \%$ were subjected to huge stressogenic impact. The elderly patients in their majority are with permanent low or variable self-esteem.

- More than half of the interviewed elderly people are with high blood pressure, and 2/3 of them suffer from other cardiovascular diseases.

- The combined influence of several risk factors is established with all of them, which determines their poor health status.

\section{Risk factors influencing infants suffering from infectious diseases:}

Infectious diseases in infants under one year of age present the other big group of hospitalized patients. Diseases accompanied with acute diarrhoea are the most common amongst them. Gastroenterites are a major problem in infancy all over the world and in the developing countries millions of deaths are due to them every year. Acute diarrhoeal diseases in our country are a major part of the infectious pathology due to climatic peculiarities, way of eating and standard of life. They depend on the infectious aetiology, social status of the population and the organisation of health care.
Fifty-three mothers accompanying their sick infants were interviewed using a questionnaire. The children were between 3 months and 1 year of age and their mothers were of 18 to 40 years of age (16). The results that were yielded were similar to those given by the elderly patients. Twenty one $(21 \%)$ of them had no medical insurance, they were with elementary education and low income, and could not pay for the medical care themselves. In $27 \%$ the income comes from social benefits. In $45 \%$ of the interviewed the income per head of the family are between 100 and 200 levs, and in 10\% - below 100 levs. In 27 of the cases there is an elderly person in the family with some chronic disease. The way of life is illustrated by the following data from the questionnaire: $21 \%$ of the families live in one-bedroom flats. In $21 \%$ of the cases the houses have no sewerage. The most common type of family is three-member one. Only $21 \%$ of the families are bigger, with five or more members. The risk of poverty for families without children is lower than that for families with children, $12.9 \%$ and $15.4 \%$ respectively for $2007(14,15)$. The risk of poverty increases with the increase of the number of the children. From $11.7 \%$ and $11.8 \%$ for families with one and with two children, it increases almost five times for families with three or more children (57\% in 2007).

Nutrition is described as sufficient but unvaried in $37 \%$ of the interviewees. $28.3 \%$ of the infants are breast-fed, $24.5 \%$ are consuming medically approved infant formulas, but $47.2 \%$ are feed with inappropriate for that age milk (unboiled cow milk, etc.)

\section{Conclusions from the questionnaire for 1-year old patients with infectious disease.}

The low income naturally leading to wrong and/or insufficient nutrition, the risk sanitary and hygienic state of the houses, and the contact of the infants with a chronically ill person in $1 / 3$ of the families, are the terrain factors for the high frequency of intestinal infectious diseases among the studied population.

\section{CONCLUSION}

Infectious diseases in the elderly patients in Varna region take their course against this unfavourable in demography and health background and under the combined action of the risk factors. In majority of the cases they are against the background of various co-morbidity, leading to higher lethality and more demands to the public health care system. As the financial resources needed for the proper health care of the elderly are not often available and infections may remain untreated. The significance of the problem is increased through the reverse transmission form the infected elderly to the younger uninfected population. A vicious circle is created where the increased needs of medical care of the elderly of $60+$ cannot be met due to the limited and wrongly used resources, and the insufficient care of the elderly leads to further increase of the expenses for health care for the whole population, especially important for the 
infants as well. The influence of these unfavourable factors is confirmed by the results of the study of some common infectious diseases (infectious gastroenteritis) in infants. Our study, despite being of limited scope, proves the necessity of a more detailed and of wider span studies of the social determinants of infectious diseases in Bulgaria, in elderly patients and infants, as well as other risk groups.

\section{REFERENCES}

1. National Report on Strategies for Social Protection and Social Inclusion (2008-2010). Available from: (ec.europa.eu/ employment_social/spsi:/docs/social_inclusion/2008/nap/bulgaria_bg.pdf).

2. $\mathrm{WHO} / \mathrm{WCK} / \mathrm{SYM} / 99.1$; Ageing and Health.

3. World Assembly on Aging; Madrid, 8-12 april 2002. Available from: http://www.who.int/hpr/ageing/ActiveAgeingPolicyFrame.pdf. http://www.un.org/esa/socdev/ageing/waa/

4. The Role of Healthcare for Reducing the Consequences of the Demographic Crisis. Report for the Consultative Council for National Security. Ministry of Health. 2006.

5. Balkanska, P. Demographic aging and dementia.Journal of Social Medicine, 4, 2002,13-15.

6. WHO. Commission of the European communities. The demographic future of Europe from challenge and opportunity. Brussels, 12.10.2006.
7. Report on the national health at the beginning of the 21-st century. Ministry of Health. 2004.

8. Kojuharova $\mathrm{M}$, at al. Acute infectious diseases in 2005-2006 (main epidemiological indicators). Information Journal NCIPD, 2008, 4-5.

9. Gospodinova, M., M. Nenova. Mediterranean Spotted Fever in adults aged over 60 years.- Scr. Sc. Medica.Varna Univ. of Med., 35, 2003, 91-94.

10. Gospodinova, M., M. Nenova. Neuroinfections in people over 60. Scr. Sc. Medica. Varna Univ. of Med., 36, 2004, 136-140.

11. Caryn, G., P.H. Kevin. Nutrition, Immunity and Infection, 2005.

12. Gaetan, G., F. Herrmann K.H. Krause. Ageing and infectious diseases in the developing world. Clinical Inf. Dis., 39, 2004, 83-91.

13. WHO regional publication. European series N 96, Food and Health in Europe: a new basis for action. Copenhagen. 2005.

14. Newscast of the National center for Health knowledge. Health promotion, 3, 1998.

15. Stojnev, E.- Nutrition, Metabolism, Ageing. AEC AMH. Sofia. 2004.

16. Belcheva, M. The role of the social factors for the occurring and dissemination of the intestinal infections. Master's thesis under the supervision of M. Nenova. MSc Program in Public Health. Varna Univ. of Med., 2006. 